\title{
Residual Wage Disparity and Coordination Unemployment
}

Julien, Benoit; Kennes, John; King, Ian

Publication date:

2004

Document version

Publisher's PDF, also known as Version of record

Citation for published version (APA):

Julien, B., Kennes, J., \& King, I. (2004). Residual Wage Disparity and Coordination Unemployment. Department of Economics, University of Copenhagen. 


\section{CAM}

\section{CAM}

Centre for Applied

Microeconometrics

Institute of Economics

University of Copenhagen

http://www.econ.ku.dk/CAMI

Residual Wage Disparity and Coordination Unemployment

Benoit Julien, John Kennes, and Ian King

2004-20

The activities of CAM are financed by a grant from

The Danish National Research Foundation 


\title{
Residual Wage Disparity and Coordination Unemployment*
}

\author{
Benoit Julien†, John Kennes; and Ian King ${ }^{\ddagger}$ \\ First Draft: June 2001 \\ Revised: November 2004
}

\begin{abstract}
We ask: how much of the observed wage dispersion, among similar workers, can be explained by a lack of coordination among employers in their hiring practices? To answer this, we construct a directed search model with homogenous workers where firms can create either good or bad jobs, are uncoordinated with their job offers, and where on-thejob search is possible. Workers can exploit ex post opportunities when determining wages. The stationary equilibrium has both productivity dispersion - different wages due to different job qualities, and contract dispersion - different wages due to different market experiences for workers, and is constrained-efficient. Job arrival rates are endogenous and, as found in empirical studies, smaller for on-the-job searchers than for unemployed workers. We calibrate the model to the US economy and compare the implied statistics with those for empirical data. The equilibrium wage distribution is hump shaped, skewed significantly to the right, and, with baseline parameters, generates residual dispersion statistics $75-90 \%$ the size of those found empirically. However, the model overestimates the values of job finding rates and underestimates the average duration of unemployment.
\end{abstract}

JEL codes: E24, E25, J31, J24, J64

\footnotetext{
${ }^{*}$ This paper was presented at the 2001 Society for Economic Dynamics meetings in Stockholm, the 2001 Australasian meetings of Econometric Society in Auckland, the 2001 Canadian Economics Association meeting in Montreal, the 2001 NBER summer institute, the University of Sydney, the 2002 meeting of the Canadian Macroeconomics Study Group, the 2003 meeting of the American Economic Association and the Dale Mortensen Conference, Sandbjerg, 2004. Comments by Debasis Bandyopadhyay, Martin Browning, Ken Burdett, Begona Dominguez, Marcel Jansen, Winfried Koeniger, Klaus Kultti, Alok Kumar, Sholeh Maani, Tim Maloney, Dale Mortensen, Stephane Pallage, Christopher Pissarides, Alan Rogers, Robert Shimer and Randall Wright are gratefully acknowledged.

${ }^{\dagger}$ Australian Graduate School of Management, benoitj@agsm.edu.au

${ }^{\ddagger}$ CAM, Institute of Economics, University of Copenhagen, John.Kennes@econ.ku.dk

${ }^{\S}$ University of Auckland, and University of Victoria, ip.king@auckland.ac.nz
} 


\section{Introduction}

It is well known that a large proportion of wage disparity cannot be explained by differences in the observed characteristics of workers. As a stylised fact, approximately two thirds of wage dispersion is "residual" - occuring within narrowly defined groups of workers. (See, for example, Katz and Autor (1999).) This has always posed a challenge to theory - particularly in light of Diamond's (1971) critique of wage dispersion, in equilibrium, with homogeneous workers. For this reason, several researchers have attributed this dispersion to unobserved heterogeneity among workers, with the implication that more detailed observations could ultimately resolve the issue.

Search theorists, on the other hand, have sought to explain this phenomenon as an equilibrium outcome with workers who are, in fact, homogeneous. Burdett and Judd (1983), for example, explore two variants of search that allow for equilibrium dispersion: non-sequential search and "noisy sequential search". More recently, Burdett and Mortensen (1998) found that equilibrium wage dispersion occurs in models with on-the-job search and parametric Poisson arrival rates for job offers. The equilibrium wage distribution implied by their model, however, counterfactually places more density on higher wages. Postel-Vinay and Robin (2002) resolve this problem by introducing productivity dispersion among firms, and add realism by allowing incumbent firms to make counteroffers to their workers when they are approached by other firms, so that a worker's wage reflects her outside option. This can generate the hump-shaped distributions observed in the data. They do, however, restort to assuming ex ante heterogeneity among workers (different valuations of leisure), and maintain the assumption that offer arrival rates are parametric - unaffected by market conditions.

In this paper we consider an alternative explanation for residual wage dispersion: a lack of coordination among employers when choosing candidates to make offers to. We argue that, in the absence of this coordination, firms may play mixed strategies when approaching candidates. When these mixed strategies are played, job offer arrival rates are endogenized, and can respond to market conditions. Also, different workers face different ex post opportunities and, therefore, different wage profiles - even when workers are identical ex ante. Furthermore, in mixed strategy equilibria, under certain reasonable conditions, firms choose different productivity levels for the jobs that they create - productivity dispersion - introducing a further source of wage dispersion that does not exist if firms are able to coordinate their offers. Particularly in the presence of on-the-job search, this process can generate wage distributions among ex ante homogeneous agents similar to those observed empirically: skewed to the right with a hump shape and with similar dispersion statisitics.

To demonstrate this point we construct a very simple model with identical workers, and where all firms are aware of the locations of all workers. 
Each worker has a fixed amount of labor to sell, and sells this labor to the highest bidder, as long as the wage is at least as high as the worker's outside option. Vacancies are created by firms, at some cost, and firms must secure workers to produce output. Once these vacancies are created, firms choose which workers to approach. In our model, within any period, firms can appoach only one worker per vacancy, and firms' choices to approach a worker are simultaneous. Although many asymmetric pure strategy equilibria exist in this model, all of which dominate mixed strategy equilibria from the firms' point of view, the only symmetric equilibrium is one in which all firms play mixed strategies. We characterize the properties of this mixed strategy equilibrium, both in a static model and in a dynamic model which allows for on-the-job-search. We then choose parameters to match US weekly wages, unemployment, and the vacancy rate, and compare the implied wage dispersion statistics with those in empirical studies. ${ }^{1}$

For the static model we identify necessary and sufficient conditions for the coexistence of both high and low productivity jobs in equilibrium. We provide complete analytical solutions for the endogenous variables, including the wage distribution, and identify two sources of wage dispersion in equilibrium: productivity dispersion (due to different job qualities) and contract dispersion (due to different outside ex post opportunities, for workers). However, since the static model only has one period, workers and vacancies have only one chance to match. With the urn-ball matching framework generated here, this implies unrealistically high unemployment rates for any reasonable parameter values. To evaluate the empirical significance of this theory, we therefore turn to a dynamic model, where workers and vacancies can match in any period and where matches are separated at a parametric rate.

For the dynamic model we establish the existence of a stationary symmetric equilibrium with on-the-job search, and the creation of both types of jobs in the equilibrium. We show that this equilibrium implies smaller offer arrival rates for on-the-job searchers than unemployed ones (as empirical studies show). For the calibrated model, we find that the standard deviation of the log wage is approximately $51 \%$ of the number reported by Katz and Autor for the entire wage distribution $-75 \%$ the $2 / 3$ attributed, by them, to residual wage dispersion. However, we find that the implied $90-10$ percentile log wage stastistic is approximately $90 \%$ of the value reported in Katz and Autor for the residual distribution. The implied wage distribution is also hump-shaped and skewed significantly to the right, as in empirical studies.

\footnotetext{
${ }^{1}$ As far as we know, this is the first attempt to match a directed search model with the data. Other studies have conducted numerical simulations (see, in particular, Cao and Shi (2000) and Julien, Kennes and King (2000)) but without specifically trying to match moments in the data.
} 


\subsection{Related Literature}

The focus on mixed strategy equilibria, when sellers face capacity constraints, has a history going back to Peters (1984). Montgomery (1991) applied this to the labor market, in a setting where firms play the role of sellers, posting a wage, and each worker can make only one job application. He also examined the existence of good and bad jobs in this setting, driving wage differentials. In a similar environment, Burdett, Shi, and Wright (2001) and Shi (2002a) investigate equilibria in which larger firms offer higher wages. Similarly, Shi (2002b) shows that, with skilled and unskilled workers and skill-biased technology, high productivity firms will offer higher wages to to unskilled workers than low productivity firms - to offset the lower probability of being hired in a high productivity job. Acemoglu and Shimer (2000) analyse a similar model, but with the added feature of nonsequential search: workers are unable to see posted wages unless they pay a cost to receive a sample of them.

In Julien, Kennes, and King (2000), as in this paper, workers play the role of sellers of labor and apply to all existing vacancies. Also, the pricing mechanism is similar: workers are able to sell their labor to the highest bidder. Hence, some wage dispersion exists, in equilibrium, due to the fact that, ex post, some workers are approached by more firms than others (contract dispersion). However, in that paper, all jobs are homogeneous, and the focus is on the role of reserve wages in finite-sized economies. We show that, as market size increases, workers' reserve wages decrease monotonically to their outside options in the limit large economy. In Julien, Kennes, and King (2002a), we draw a link between this wage determination mechanism and the rule proposed by Mortensen (1982) in the context of cooperative games. Albrecht, Gautier, and Vroman (2003) demonstrate that, when workers are able to make multiple applications in the environments considered by Montgomery (1991) and Burdett, Shi and Wright (2001), the equilibrium wage structure mimics the bidding structure we use here. In Julien, Kennes, and King (2001a) we consider a setting where, in a prior stage of the game, workers can choose whether to auction or post wages. Collectively, all these papers have recently come under the heading of "directed search". ${ }^{2}$ A common feature of these models is the endogenous probabilistic matching structure which has properties similar to the matching functions discussed, for example, in Pissarides (2000).

Section 2 presents and analyses the static model. The dynamic model is introduced, and its features are analysed, in Section 3. Section 4 presents the calibrated version of the model, and Section 5 concludes. The proof of one of the propositions and its corollary are contained in the Appendix.

\footnotetext{
${ }^{2}$ The directed search literature contains several other papers, not all of which have their roots in this coordination problem. See, for example, Moen (1997). For recent surveys, see King (2003) and Rogerson, Shimer, and Wright (2004).
} 


\section{The Static Model}

We consider a simple economy with a large number $N$ of identical, risk neutral, job candidates where each candidate has one indivisible unit of labor to sell. There are $M_{i}=\phi_{i} N$ vacancies of two types: $i \in\{1,2\}$, where $\phi_{i} \geq 0$, and are determined by free entry. The productivity of a worker is $y_{0}$ if unemployed (we normalize $y_{0}=0$ ) and $y_{i}>0$ if employed in a job of type $i$, where $y_{2}>y_{1}$. It costs $k_{i}$ to create a vacancy, where $k_{2}>k_{1}$ and $y_{i}>k_{i} \geq 0$ for all $i$. Each vacancy can approach only one candidate. ${ }^{3}$ The order of play is as follows. Given the number of workers $N, M_{i}$ vacancies of each type $i$ enter the market. Once the number of entrants has been established, vacancies choose which candidate to approach. Once vacancies have been assigned to candidates, wages are determined through a bidding game. That is, given the number of vacancies (of each type) that have approached the worker, the worker conducts an auction to determine which firm to work for. We solve the model using backwards induction.

\subsection{Wage Determination}

Once vacancies have been assigned to candidates, different candidates face, in general, different ex post opportunities. Those that have no vacancies assigned to them are, of course, unemployed and receive only their outside option $y_{0}=0$. All other candidates allocate their labor according to a bidding game, where each candidate sells his labor to the highest bidder, as long as the highest bid at least matches the outside option. If only one vacancy is assigned to the candidate, then the highest bid will be exactly the outside option. When at least two vacancies are assigned to the candidate, the bidding game determines that the candidate works at the vacancy with the highest valuation for the worker, and is paid the amount of the second highest valuation from among the vacancies that have been assigned to him. ${ }^{4}$ If, for example, at least two high productivity vacancies are assigned

\footnotetext{
${ }^{3}$ The heurisitic justification for this assumption, discussed at some length in Julien, Kennes, and King (2000), is as follows. When firms make job offers to workers, they are often committed for some length of time, while the worker considers the offer. We take this as given, institutionally, in this paper. Thus, if a firm has only one vacancy, it can make an offer to, at most, one worker at a time. In the static model there is, of course, only one time period. This appears as a very strong assumption in this case. However, in the calibration of the dynamic model below, each period lasts for one week. Thus, when a firm makes an offer, the worker can hold that offer for one week. In New Zealand, for example, labor law requires that firms give candidates one week to consider offers.

${ }^{4}$ We justify the usage of this mechanism in following ways. First, we believe that auction mechanisms are natural to consider in markets where, as here, each buyer expects to face multiple sellers. In Julien, Kennes, and King (2001a) we show, in a game where sellers can choose whether to to post prices or to auction with a reserve price, the auction choice is an equilibrium one. In particular, if they can commit to a mechanism ex ante, then the auction emerges as the dominant strategy equilibirum. In Julien, Kennes, and
} 
to the candidate then the candidate will work at one of these jobs (with equal probablility) and will be paid $y_{2}$. If, alternatively, only one high productivity, and at least one low productivity vacancies, are assigned then the candidate will work in the high productivity job but will be paid only $y_{1}$. If no high productivity vacancies, but at least two low productivity vacancies are assigned then the candidate will work in one of the low producitivity jobs (with equal probability) and will be paid $y_{1}$.

Thus, in equilibrium, the wage $w_{i}^{j}$ of a worker who is employed in a job of productivity $i$, and whose second best vacancy had productivity $j$, is given by:

$$
w_{i}^{j}=y_{j}
$$

for all $i, j \in\{0,1,2\}$. (For notational convenience, we denote the "wage" of an unemployed worker to be $w_{0}^{0}$.)

\subsection{Frictional Assignment of Vacancies to Workers}

We now consider the problem, facing firms, of which candidates to approach. All firms understand the wage determination mechanism, above, that operates once vacancies have been assigned. Also, all firms know the numbers of each type of vacancy that have been created. Firms choose candidates to approach in a simultaneous move game. As mentioned in the Introduction, there are many asymmetric pure strategy equilibria, where vacancies are uniquely assigned to candidates. However, implementation of any one of these equilibria requires coordination among the firms. In large economies such as this, coordination becomes practically impossible. Therefore, as has become standard in directed search environments, here we restrict our attention to the unique symmetric mixed strategy equilibrium in which each buyer of each type randomizes over sellers (which are identical). ${ }^{5}$ Consequently, the probability $p_{i}$ that a worker is approached by a vacancy of maximum productivity $y_{i}$ is given by:

$$
\begin{aligned}
& p_{0}=e^{-\phi_{1}} e^{-\phi_{2}} \\
& p_{1}=e^{-\phi_{2}}\left(1-e^{-\phi_{1}}\right) \\
& p_{2}=\left(1-e^{-\phi_{2}}\right)
\end{aligned}
$$

King (2000), we show that equilibrium reserve wages converge to the outside option as market size increases. Thus, in large markets such as the one considered in this paper, the outside option is the equilibrium reserve. Also, work by Lu and McAfee (1996) has shown that, when sellers can choose selling mechanisms, auctions will drive out bargaining in the sense that no evolutionary-stable equilibrium with any sellers bargaining exists in large markets. For further discussion on mechanism selection in similar environments, see McAfee (1993), Wang (1993), Kultti (1999), Julien, Kennes, and King (2002b), and Coles and Eeckhout (2003).

${ }^{5}$ In this paper we do not model this game explicitly. For a derivation and proof of existence of this mixed strategy equilibrium, in a more general environment, we refer the reader to Julien, Kennes, and King (2005). 


\subsubsection{Wage Disparity}

It also follows that, in a large market, from the pool of vacant jobs of productivity $y_{i}$, a candidate obtains either (i) no offer, (ii) one offer, and (iii) multiple offers with probabilities $e^{-\phi_{i}}, \phi_{i} e^{-\phi_{i}}$ and, $1-e^{-\phi_{i}}-\phi_{i} e^{-\phi_{i}}$, respectively. Therefore, the wage distribution of the static model, $\Omega_{s}$, is given by the following matrix:

$$
\Omega_{s} \equiv\left[w_{i}^{j}, p_{i}^{j}\right]=\left[\begin{array}{cl}
w_{0}^{0}=0, & p_{0}^{0}=e^{-\phi_{1}} e^{-\phi_{2}} \\
w_{1}^{0}=0, & p_{1}^{0}=\phi_{1} e^{-\phi_{1}} e^{-\phi_{2}} \\
w_{1}^{1}=y_{1}, & p_{1}^{1}=\left(1-e^{-\phi_{1}}-\phi_{1} e^{-\phi_{1}}\right) e^{-\phi_{2}} \\
w_{2}^{0}=0, & p_{2}^{0}=\phi_{2} e^{-\phi_{2}} e^{-\phi_{1}} \\
w_{2}^{1}=y_{1}, & p_{2}^{1}=\phi_{2} e^{-\phi_{2}}\left(1-e^{-\phi_{1}}\right) \\
w_{2}^{2}=y_{2}, & p_{2}^{2}=\left(1-e^{-\phi_{2}}-\phi_{2} e^{-\phi_{2}}\right)
\end{array}\right]
$$

where $p_{i}^{j}$ denotes the probability that worker obtains a wage $w_{i}^{j}$.

If the numbers of vacancies are given exogenously (i.e., if $\phi_{1}$ and $\phi_{2}$ were parameters) then (2.3) would represent the final solution of the model. Examining (2.3), it is clear that wage dispersion has two sources: contract dispersion and productivity dispersion. For example, the difference in the wages $w_{1}^{1}=y_{1}$ and $w_{1}^{0}=0$ is due entirely to contract dispersion: in both cases, the productivity of the job is low, but workers who earn $w_{1}^{1}$ had a second-best offer from another low productivity job whereas workers who earn $w_{1}^{0}$ did not. In order to receive the highest wage $w_{2}^{2}=y_{2}$, workers need to be on the right end of both contract and productivity dispersion: the presence of at least one high productivity vacancy is required to make this wage technically feasible, and the presence of at least one other high productivity vacancy, as a second-best offer is required to make this wage an equilibrium outcome. It is also clear that contract dispersion can be at least as important to workers as productivity dispersion. For example, a worker in a high productivity job earns a wage equal to $w_{2}^{0}=0$ with probability $p_{2}^{0}$ while a worker in low productivity job earns a higher wage $w_{1}^{1}=y_{1}$ of with probability $p_{1}^{1}$. Both of these probabilities are positive if $\phi_{1}, \phi_{2}>0$. We now turn to the determination of $\phi_{1}$ and $\phi_{2}$.

\subsection{Vacancy Entry}

We now consider the first stage of the game, where firms decide how many vacancies, of each type, to create. We assume that each firm can create one vacancy. (Thus, we use the terms "firm" and "vacancy" interchangeably depending on the context.) The profit of a firm is equal to its output minus its vacancy creation cost and the wage it pays to the worker. Therefore, the profit $\pi_{i}^{j}$ of a vacant job of productivity $y_{i}$ that makes an offer to a worker 
who has a best rival offer of productivity $y_{j}$ is given by:

$$
\pi_{i}^{j}=\max \left\{y_{i}-y_{j}, 0\right\}-k_{i}
$$

Let $q_{i}^{j}$ be the probability that a firm earns a profit equal to $\pi_{i}^{j}$. Thus, the expected profit $\pi_{i}$ of a vacant job of productivity $y_{i}$ is given by:

$$
\begin{aligned}
& \pi_{1}=\max \left\{q_{1}^{0} y_{1}-k_{1}, 0\right\} \\
& \pi_{2}=\max \left\{q_{2}^{0} y_{2}+q_{2}^{1}\left(y_{2}-y_{1}\right)-k_{2}, 0\right\}
\end{aligned}
$$

The probability that a vacant job does not face competition from a rival job of productivity $y_{i}$ is given by $e^{-\phi_{i}}$. Therefore $q_{1}^{0}=q_{2}^{0}=e^{-\phi_{1}} e^{-\phi_{2}}$ is the probability that the vacant job does not face a rival vacant job of either productivity, and $q_{2}^{1}=\left(1-e^{-\phi_{1}}\right) e^{-\phi_{2}}$ is the probability that a vacant job faces a low productivity rival but not a high productivity rival.

The supply of vacant jobs of productivity $y_{i}$ is determined by free entry, so the expected profit $\pi_{i}$ of a vacant job of productivity $y_{i}$ is equal to zero in equilibrium:

$$
\pi_{1}=\pi_{2}=0
$$

The assumption that the output of a particular type of job is greater than the cost of the job vacancy does not guarantee that the supply of jobs of that type is positive. (For example, it is easy to see that $q_{1}^{0} y_{1}-k_{1}$ can be negative if $\phi_{2}$ is sufficiently large - making $q_{1}^{0}$ sufficiently small.) Therefore we do not know, based on our present assumptions, whether or not the two different jobs will exist in equilibrium. The following proposition presents a necessary and sufficient condition for the existence of this type of technology dispersion.

Proposition 1 For given values of $\left(y_{1}, y_{2}, k_{1}, k_{2}\right)$ a unique equilibrium exists with a strictly positive number of both types of jobs if and only if the following condition holds:

$$
0<\frac{k_{2}}{y_{2}}-\frac{k_{1}}{y_{1}}<\frac{y_{2}-y_{1}}{y_{2}}
$$

Proof. In any equilibrium with both types of vacancies, the expected profit for each type of vacancy is given by

$$
\pi_{1}=e^{-\phi_{1}} e^{-\phi_{2}} y_{1}-k_{1}=0 \text { by equations }(2.5) \text { and }(2.7)
$$

and

$\pi_{2}=e^{-\phi_{1}} e^{-\phi_{2}} y_{2}+\left(1-e^{-\phi_{1}}\right) e^{-\phi_{2}}\left(y_{2}-y_{1}\right)-k_{2}=0$ by equations $(2.6)$ and (2.7) 
Solving these simultaneously yields the unique solution:

$$
\phi_{1}=\ln \left(y_{1} / k_{1}\right)-\ln \left(\left(y_{2}-y_{1}\right) /\left(k_{2}-k_{1}\right)\right)
$$

and

$$
\phi_{2}=\ln \left(\left(y_{2}-y_{1}\right) /\left(k_{2}-k_{1}\right)\right)
$$

It follows that $\phi_{1}, \phi_{2}>0$ iff $y_{2}-k_{2}>y_{1}-k_{1}$ and $k_{1} / y_{1}<k_{2} / y_{2}$, which imply the condition above.

The left side of this condition implies that marginal costs (relative to productivity) are increasing. This ensures the existence of some bad jobs in equilibrium. The right hand side of the condition states that the percentage productivity advantage from a good job is larger than the increment in marginal costs incurred from producing a good job. This ensures that the supply of high productivity jobs is positive.

\subsection{Properties of the Equilibrium}

When the condition of Proposition 1 holds, then equations (2.3), (2.7), (2.8), and (2.9) completely solve for the equilibrium payoff structure in the static model. Also, the value of the unemployment rate in this equilibrium $\left(p_{0}=\right.$ $e^{-\phi_{1}} e^{-\phi_{2}}$ ) can be found from equations (2.5) and (2.7):

$$
p_{0}=\frac{k_{1}}{y_{1}}
$$

This simple expression makes it clear that, in the equilibrium where both types of jobs exist, it is the marginal cost (relative to productivity) of bad jobs that determines unemployment. Good jobs produce more, but are costly to create. Once the number of good jobs is determined, through (2.9), then bad jobs (which are relatively cheap to create) fill in to the point were no further job creation is warranted in equilibrium. ${ }^{6}$

Although we do not prove it here, it is easy to show that the allocation in this equilibrium is constrained-efficient in the sense that a planner who can choose entry, but faces the same coordination friction, would choose precisely the same allocation. ${ }^{7}$ The matching rate for good jobs in this allocation is $\left(1-e^{-\phi_{2}}\right)$, which is different from the rate for bad jobs: $e^{-\phi_{2}}\left(1-e^{-\phi_{1}}\right)$. This accords with the results found by Davis (2001) although, here, these matching rates are obtained in equilibrium. Notice, also, the aggregate matching function $N\left(1-e^{-\left(\phi_{1}+\phi_{2}\right)}\right)$ has constant returns to scale.

\footnotetext{
${ }^{6}$ In the absence of job heterogeneity, the unemployment rate becomes simply $p_{0}=k / y$.

${ }^{7}$ See Julien, Kennes, and King (2001b) for efficiency proofs for both the static and dynamic models.
} 
Given the existence of both good and bad jobs in equilibrium, with higher wages, on average, for good jobs, it is natural to allow for on-the-job search in dynamic versions of the model.

\section{The Dynamic Model with On-the-Job Search}

There is large number, $N$, of identical risk neutral workers facing an infinite horizon, perfect capital markets, and a common discount factor $\beta$. In each time period, each worker has one indivisible unit of labor to sell. Since we focus on stationary equilibria, we drop the time subscript and, whenever needed, we use an prime (') to refer to period $t+1$, two primes for $t+2$, and so on. At the start of each period there exist $E_{i}$ workers in jobs of producing $y_{i}>0$ where $i \in\{1,2\}$., $y_{2}>y_{1}$, and $\left(N-E_{1}-E_{2}\right)$ unemployed workers, with production $y_{0}=0$. Also, at the beginning of each period, there exist $M_{i}=\phi_{i}\left(N-E_{1}-E_{2}\right)$ vacant jobs of each productivity type directed at unemployed workers and $\widehat{M}_{2}=\widehat{\phi}_{2} E_{1}$ high productivity vacant jobs directed at employed workers in jobs of productivity $y_{1} .8$ In each period a vacant job has a capital cost of $k_{i}$ where $k_{2}>k_{1}$. Any match in any period may dissolve in at the beginning of the subsequent period with fixed probability $\rho \in(0,1)$. In each period, any vacancy can enter negotiations with at most one worker.

Within each period, the order of play is as follows. At the beginning of the period, given the state, new vacancies enter. Next, unemployed workers and workers who are employed in low quality jobs send applications, stating their actual state of employment, to all vacancies costlessly. ${ }^{9}$ Once the number of entrants has been established, and job applications received, vacancies choose which workers to approach. Once new vacancies have been assigned to candidates, wage contracts are determined through the auction mechanism. After this, production occurs and each agent receives the amount agreed to in the contract. At the end of the period, a fraction $\rho$ of existing matches dissolves.

\subsection{Wage Contract Determination}

Let $\Lambda_{i}$ denote the total expected discounted value of a match between a worker and a job of productivity $y_{i}$ at the start of any period, with $\Lambda_{0}$ representing the reserve value associated with an unemployed worker. Through

\footnotetext{
${ }^{8}$ Note that no low productivity vacant jobs are directed at employed workers in high productivity jobs. As should be clear, this would never be profitable since this would entail two high productivity jobs competing for the same worker, with Bertrand competition driving the wage up to $y_{2}$.

${ }^{9} \mathrm{We}$ assume here that verification of employment status is easy for employers to do, and is part of the cost of vacancy creation.
} 
the auction, in a way entirely analogous to the static model, the value of a worker's wage contract $W_{i}^{j}$ is equal to the expected discounted value $\Lambda_{j}$ of a match between the worker and the worker's second best available job offer:

$$
W_{i}^{j}=\Lambda_{j}
$$

The per period wage is assumed to be constant over the employment duration.

\subsection{Frictional Assignment of Vacancies to Workers}

Unemployed workers have a reserve value of $\Lambda_{0}$ while workers in low productivity jobs have a reserve value of $\Lambda_{1}$. The workers are distinguishable only by their employment state. As in the static model, we restrict attention to the unique symmetric mixed strategy equilibrium in which each vacancy randomises over each relevant group of workers. Consequently, the new hires of $H_{2}$ high productivity workers and $H_{1}$ low productivity workers are given respectively by:

$$
\begin{aligned}
& H_{2}=\left(N-E_{1}-E_{2}\right) p_{2}+E_{1} \widehat{p}_{2} \\
& H_{1}=\left(N-E_{1}-E_{2}\right) p_{1}-E_{1} \widehat{p}_{2}
\end{aligned}
$$

where $p_{2}=\left(1-e^{-\phi_{2}}\right), p_{1}=\left(1-e^{-\phi_{1}}\right) e^{-\phi_{2}}$ and $\widehat{p}_{2}=\left(1-e^{-\widehat{\phi}_{2}}\right)$. The term $E_{1} \widehat{p}_{2}$ in these equations represents the "raiding" of workers from low productivity jobs into high productivity ones.

The fraction $\rho$ of all jobs dissolve at the end of the period, therefore, the supply of candidates of each type evolves according to the following transition equations:

$$
E_{i}^{\prime}=(1-\rho)\left(E_{i}+H_{i}\right) \quad i \in\{1,2\}
$$

\subsection{The Value of Unmatched and Matched Workers}

The randomness of job offers implies that the expected value of being a candidate in every period is determined by the expected wage contract one can obtain depending on whether no, only one, or multiple offers from vacancies of either type are received. The expected present value of a worker without a job at the start of a period is:

$$
V=p_{0}^{0} W_{0}^{0}+p_{1}^{0} W_{1}^{0}+p_{2}^{0} W_{2}^{0}+p_{1}^{1} W_{1}^{1}+p_{2}^{1} W_{2}^{1}+p_{2}^{2} W_{2}^{2}
$$

From the auction equation (3.1), $W_{0}^{0}=W_{1}^{0}=W_{2}^{0}=\Lambda_{0}, W_{1}^{1}=W_{2}^{1}=\Lambda_{1}$ and $W_{2}^{2}=\Lambda_{2}$, therefore

$$
V=\left(p_{0}^{0}+p_{1}^{0}+p_{2}^{0}\right) \Lambda_{0}+\left(p_{1}^{1}+p_{2}^{1}\right) \Lambda_{1}+p_{2}^{2} \Lambda_{2}
$$


where $p_{0}^{0}+p_{1}^{0}+p_{2}^{0}=\left(1+\phi_{1}+\phi_{2}\right) e^{-\phi_{1}} e^{-\phi_{2}}$ is the probability that a worker has one or fewer offers, $p_{1}^{1}+p_{2}^{1}=e^{-\phi_{2}}\left(1-\phi_{1} e^{-\phi_{1}}-e^{-\phi_{1}}\right)+\phi_{2} e^{-\phi_{2}}\left(1-e^{-\phi_{1}}\right)$ is the probability of multiple offers only one of which is possibly good, and $p_{2}^{2}=1-e^{-\phi_{2}}-\phi_{2} e^{-\phi_{2}}$ is the probability of multiple good offers.

The value of being an unemployed worker in the next period determines the value of a unmatched worker at the end of a period:

$$
\Lambda_{0}=\beta V^{\prime} .
$$

where $\Lambda_{0}$ also gives the outside option of all workers in any wage negotiations with a single firm.

The total surplus of a high productivity job is equal to the output of a high productivity job plus the discounted future flow of income from such a job weighted by the probability of an exogenous job separation into unemployment:

$$
\begin{aligned}
\Lambda_{2}= & y_{2}+\beta\left[\rho V^{\prime}+(1-\rho) y_{2}\right] \\
& +\beta^{2}(1-\rho)\left[\rho V^{\prime \prime}+(1-\rho) y_{2}\right]+\ldots
\end{aligned}
$$

Wages in low productivity jobs are determined with the understanding that the worker will get the increase of surplus associated with any potential favourable future bargain between the worker and a high productivity job during the worker's tenure at a low productivity job. Therefore, the expected present value of being a worker in a low productivity job must incorporate the probability of moving into a higher paying (high productivity) job in a subsequent period. Hence

$$
\begin{aligned}
\Lambda_{1}= & y_{1}+\beta\left[\rho V^{\prime}+(1-\rho) X^{\prime}\right] \\
& +\beta^{2}(1-\rho)\left[\rho V^{\prime \prime}+(1-\rho) X^{\prime \prime}\right]+\ldots
\end{aligned}
$$

where $X^{\prime}=\left(\widehat{p}_{1}^{1} y_{1}+\widehat{p}_{2}^{1} \Lambda_{1 t}+\widehat{p}_{2}^{2} \Lambda_{2 t}\right)$ is the present value of being a candidate in the market while employed in a low productivity job and allows for three possible outcomes: $\widehat{p}_{1}^{1}=e^{-\widehat{\phi}_{2}}$ (the probability that the employed worker is not recruited), $\widehat{p}_{2}^{1}=\widehat{\phi}_{2} e^{-\widehat{\phi}_{2}}$ (the probability that the employed worker is recruited by one good job), and $\widehat{p}_{2}^{2}=1-e^{-\widehat{\phi}_{2}}-\widehat{\phi}_{2} e^{-\widehat{\phi}_{2}}$ (the probability that the worker is recruited by one or more high productivity jobs).

In the stationary equilibrium:

$$
\begin{aligned}
\Lambda_{0} & =\beta V \\
\Lambda_{1} & =\frac{y_{1}+\beta\left(\rho V+(1-\rho)\left(1-\widehat{\phi}_{2} e^{-\widehat{\phi}_{2}}-e^{-\widehat{\phi}_{2}}\right) \Lambda_{2}\right)}{1-\beta(1-\rho)\left(\widehat{\phi}_{2} e^{-\widehat{\phi}_{2}}+e^{-\widehat{\phi}_{2}}\right)} \\
\Lambda_{2} & =\frac{y_{2}+\beta \rho V}{(1-\beta(1-\rho))}
\end{aligned}
$$


The equilibrium values of $\Lambda_{0}$ and $\Lambda_{2}$, in (3.9) and (3.11), are standard present values. The equilibrium value $\Lambda_{1}$ in (3.10), however, deserves some comment. The term $\left(\widehat{\phi}_{2} e^{-\widehat{\phi}_{2}}+e^{-\widehat{\phi}_{2}}\right)$ is the probability with which a candidate doing on-the-job search is not raided by a better paying job. Therefore $\beta(1-\rho)\left(\widehat{\phi}_{2} e^{-\widehat{\phi}_{2}}+e^{-\widehat{\phi}_{2}}\right)$ is the adjusted discount factor for such a candidate, accounting for the exogenous probability $(1-\rho)$ of not being separated and the endogenous probability of not being separated by a better paying job. The equilibrium value $\Lambda_{1}$ is the present discounted value of being paid $y_{1}$ plus the discounted next period gamble of being exogenously separated and becoming an unemployed candidate $(\rho V)$, and of being only endogenously separated by a better paying job offer $(1-\rho)\left(1-\widehat{\phi}_{2} e^{-\widehat{\phi}_{2}}-e^{-\widehat{\phi}_{2}}\right) \Lambda_{2}$.

In the stationary equilibrium, the expected present value of being a candidate on the market for an unemployed worker can be expressed as:

$$
V=\Lambda_{2}-\left(\Lambda_{1}-\Lambda_{0}\right)\left(1+\phi_{1}+\phi_{2}\right) e^{-\phi_{1}} e^{-\phi_{2}}-\left(\Lambda_{2}-\Lambda_{1}\right)\left(1+\phi_{2}\right) e^{-\phi_{2}}
$$

Using equations (3.9), (3.10), (3.11) and above yields:

$$
V=\frac{1}{(1-\beta)}\left(y_{2}-(1-\beta(1-\rho))\left[\left(1+\phi_{1}+\phi_{2}\right) k_{1}+\frac{e^{-\phi_{2}}}{e^{-\hat{\phi}_{2}}}\left(1+\phi_{2}\right) k_{2}\right]\right)
$$

This is the expected present value of being a candidate on the market for an unemployed worker, expressed as a function of the parameters $\left(\beta, \rho, y_{2}, k_{1}, k_{2}\right)$ and the vacancy ratios $\phi_{1}, \phi_{2}$ and $\hat{\phi}_{2}$. Although $y_{1}$ does not appear explicitly in this expression, we show, below, that the ratios $\phi_{1}, \phi_{2}$ and $\hat{\phi}_{2}$ are implicit functions of the parameters, including $y_{1}$. We now turn attention to the determination of these ratios.

\subsection{Equilibrium Vacancies}

The expected profit $\Pi_{i}$ of a job of productivity $y_{i}$ making an offer to an unemployed worker satisfies:

$$
\begin{aligned}
\Pi_{1}= & \max \left\{\left(\Lambda_{1}-\Lambda_{0}\right) e^{-\phi_{1}} e^{-\phi_{2}}-k_{1}, 0\right\} \\
\Pi_{2}= & \max \left\{\left(\Lambda_{2}-\Lambda_{0}\right) e^{-\phi_{1}} e^{-\phi_{2}}\right. \\
& \left.+\left(\Lambda_{2}-\Lambda_{1}\right)\left(1-e^{-\phi_{1}}\right) e^{-\phi_{2}}-k_{2}, 0\right\}
\end{aligned}
$$

where $e^{-\phi_{1}} e^{-\phi_{2}}$ is the probability that a low or high productivity job does not face a rival, and $\left(1-e^{-\phi_{1}}\right) e^{-\phi_{2}}$ is the probability that a high productivity job faces only a low productivity rival.

The expected profit of an offer by a high productivity to a worker in a low productivity job is given by:

$$
\widehat{\Pi}_{2}=\max \left\{\left(\Lambda_{2}-\Lambda_{1}\right) e^{-\widehat{\phi}_{2}}-k_{2}, 0\right\}
$$


where $e^{-\widehat{\phi}_{2}}$ is the probability that high productivity job does not face a competing offer from a rival high productivity job. The supply of vacant jobs of productivity $y_{i}$ is determined by free entry. Thus:

$$
\Pi_{1}=\Pi_{2}=\widehat{\Pi}_{2}=0
$$

The free entry conditions imply that

$$
\begin{gathered}
\Lambda_{1}-\Lambda_{0}=\frac{k_{1}}{e^{-\phi_{1}} e^{-\phi_{2}}} \\
\left(\Lambda_{2}-\Lambda_{0}\right) e^{-\phi_{1}} e^{-\phi_{2}}+\left(\Lambda_{2}-\Lambda_{1}\right)\left(1-e^{-\phi_{1}}\right) e^{-\phi_{2}}=k_{2} \\
\Lambda_{2}-\Lambda_{1}=\frac{k_{2}}{e^{-\hat{\phi}_{2}}}
\end{gathered}
$$

which imply that $\Lambda_{2}>\Lambda_{1}>\Lambda_{0}$ for all $\phi$.

The stationary equilibrium values of the endogenous variables $V, \Lambda_{0}, \Lambda_{1}$, $\Lambda_{2}, \phi_{1}, \phi_{2}$, and $\widehat{\phi}_{2}$ are determined by equations (3.9)-(3.12) and (3.17)-(3.19). The following proposition summarizes key properties of the stationary equilibrium.

Proposition 2 For given values of $\left(\beta, \rho, y_{1}, y_{2}, k_{1}, k_{2}\right)$, a unique Stationary Equilibrium exists where

a) All types of vacancies are created: $\left\langle\phi_{1}, \phi_{2}, \widehat{\phi}_{2}\right\rangle>>0$ iff

$$
k_{1}<\left(y_{1}+\beta(1-\rho) k_{2}\left(\phi_{2}-\widehat{\phi}_{2}\right)\right) e^{-\phi_{2}} \text { and } k_{2}<\frac{y_{2}-y_{1}}{1-\beta(1-\rho)}
$$

b) Only vacancies targeted at unemployed workers are created:

$$
\begin{aligned}
& \left\langle\phi_{1}, \phi_{2}\right\rangle>>0 \text { and } \widehat{\phi}_{2}=0 \text { iff } \\
& k_{1}<\left(y_{1}+\beta(1-\rho) k_{2}\left(\phi_{2}-\widehat{\phi}_{2}\right)\right) e^{-\phi_{2}} \text { and } \\
& \frac{y_{2}-y_{1}}{1-\beta(1-\rho)} \leq k_{2}<\frac{y_{2}-y_{1}+k_{1}}{1-\beta(1-\rho)\left(1+\ln \left(\frac{k_{2}-k_{1}}{k_{2}}\right)\right)}
\end{aligned}
$$

c) Only high productivity vacancies targeted at unemployed workers are created: $\left\langle\phi_{1}, \widehat{\phi}_{2}\right\rangle=0$ and $\phi_{2}>0$ iff

$$
\begin{aligned}
& k_{1} \geq\left(y_{1}+\beta(1-\rho) k_{2}\left(\phi_{2}-\widehat{\phi}_{2}\right)\right) e^{-\phi_{2}} \text { and } \\
& \frac{y_{2}-y_{1}}{1-\beta(1-\rho)} \leq k_{2}<\frac{y_{2}-y_{1}+k_{1}}{1-\beta(1-\rho)\left(1+\ln \left(\frac{k_{2}-k_{1}}{k_{2}}\right)\right)}
\end{aligned}
$$


d) Only low productivity vacancies are created: $\left\langle\phi_{2}, \widehat{\phi}_{2}\right\rangle=0$ and

$$
\begin{aligned}
& \phi_{1}>0 \text { iff } \\
& k_{1}<\left(y_{1}+\beta(1-\rho) k_{2}\left(\phi_{2}-\widehat{\phi}_{2}\right)\right) e^{-\phi_{2}} \text { and } \\
& k_{2}>\frac{y_{2}-y_{1}+k_{1}}{1-\beta(1-\rho)\left(1+\ln \left(\frac{k_{2}-k_{1}}{k_{2}}\right)\right)}
\end{aligned}
$$

This proposition places bounds on the costs of vacancy creation, relative to productivity differentials, for firms to have incentives to create profitable vacancies. For all types of vacancies to be created in equilibrium (part (a)), for example, there are only upper bounds on $k_{1}$ and $k_{2}$. For equilibria with both high and low productivity vacancies, but no on-the-job-search (part (b)) there are both upper and lower bounds on $k_{2}$. In this equilibrium, $k_{2}$ is low enough to induce the creation of high productivity jobs aimed at unemployed workers, but too high for the creation of of these jobs aimed at employed workers. Notice that, in this equilibrium, low productivity jobs are created and there is no on-the-job search - so there is no threat of losing workers to higher paying jobs, once hired. We should expect, then, that more low productivity jobs would be created in this environment. This basic intuition is verified in the numerical analysis below. Parts (c) and (d) of the Proposition identify conditions under which only one type of job will be created in equilibrium (high and low productivity jobs respectively).

In this paper we focus on the equilibrium, identified in part (a) of Proposition 2 , where all three types of vacancies are created. The following corollary identifies an important feature of this equilibrium.

Corollary 1 In the equilibrium where all types of vacancies are created, the job arrival rate for unemployed workers is greater than for on-the-job searchers: $\left(1-e^{-\left(\phi_{1}+\phi_{2}\right)}\right)>\left(1-e^{-\widehat{\phi_{2}}}\right)>0$.

This corollary underscores the endogeneity of the matching process in the model. By way of contrast, models with on-the-job search and purely random matching use parametric rates for both unemployed workers and onthe-job searchers (typically denoted $\lambda_{0}$ and $\lambda_{1}$ respectively). ${ }^{10}$ In line with empirical work on these rates, (Kiefer and Neumann (1993)) these models usually impose the condition that $\lambda_{0}>\lambda_{1}$. Corollary 1 shows that this is justifiable as an equilibrium phenomenon, and how this relates to labor market tightness conditions and, ultimately, the parameters $\left(\beta, \rho, y_{1}, y_{2}, k_{1}, k_{2}\right)$.

\footnotetext{
${ }^{10}$ For example, Burdett and Mortensen (1998).
} 


\subsubsection{Steady State Employment and Unemployment}

The transition equations for the flow of workers between different employment states can be used to derive the steady state end-of-period employment levels. In a stationary equilibrium, the fraction of workers in each productivity state (after the matching has taken place) is given by:

$$
\begin{aligned}
n_{0} & =\frac{\rho e^{-\phi_{1}} e^{-\phi_{2}}}{1-(1-\rho) e^{-\phi_{1}} e^{-\phi_{2}}} \\
n_{1} & =\frac{\left(1-\left(1-n_{0}\right)(1-\rho)\right) e^{-\phi_{2}}\left(1-e^{-\phi_{1}}\right)}{\rho+(1-\rho)\left(1-e^{-\widehat{\phi}_{2}}\right)} \\
n_{2} & =1-n_{1}-n_{0}
\end{aligned}
$$

where $n_{i}=\left(E_{i}+H_{i}\right) / N, i=1,2$.

\subsubsection{The Wage Distribution}

In order to obtain a wage distribution, the periodic wages in the stationary distribution must be obtained. As mentioned above, we assume here that wage contracts specify constant wages over the expected length of the contract. Using equation (3.1), these wages are determined by:

$$
\begin{aligned}
w_{0}^{0} & =0 \\
\frac{w_{2}^{j}+\beta \rho V}{1-\beta(1-\rho)} & =W_{2}^{j}=\Lambda_{j} \forall j \in\{0,1,2\} \\
\frac{w_{1}^{j}+\beta\left(\rho V+(1-\rho)\left(1-\widehat{\phi}_{2} e^{-\widehat{\phi}_{2}}-e^{-\widehat{\phi}_{2}}\right) \Lambda_{2}\right)}{1-\beta(1-\rho)\left(\widehat{\phi}_{2} e^{-\widehat{\phi}_{2}}+e^{-\widehat{\phi}_{2}}\right)} & =W_{1}^{j}=\Lambda_{j} \forall j \in\{0,1\}
\end{aligned}
$$

where $w_{i}^{j}$ denotes the wage per period of a worker under wage contract $W_{i}^{j}$. Thus, the wage distribution $\Omega_{d}$ of the dynamic model with on-the-job search is given by: 


$$
\Omega_{d} \equiv\left[w_{i}^{j}, n_{i}^{j}\right]=\left[\begin{array}{l}
w_{0}^{0}=0 \\
w_{1}^{0}=\Lambda_{0}-\beta(\rho V \\
\left.+(1-\rho)\left(\Lambda_{2}\left(1-\left(1+\widehat{\phi}_{2}\right) e^{-\widehat{\phi}_{2}}\right)+\Lambda_{0}\left(1+\widehat{\phi}_{2}\right) e^{-\widehat{\phi}_{2}}\right)\right) \\
w_{1}^{1}=y_{1} \\
w_{2}^{0}=\Lambda_{0}-\beta\left(\rho V+(1-\rho) \Lambda_{0}\right) \\
w_{2}^{1}=\Lambda_{1}-\beta\left(\rho V+(1-\rho) \Lambda_{1}\right) \\
w_{2}^{2}=y_{2} \\
n_{0}^{0}=n_{0} \\
n_{1}^{0}=\left(\left[\rho+(1-\rho) n_{0}\right] \phi_{1} e^{-\phi_{1}}\right) \\
\\
n_{1}^{1}=n_{1}-n_{1}^{0} \\
n_{2}^{0}=\left(1+n_{0}(1-\rho) / \rho\right) \phi_{2} e^{-\phi_{1}} e^{-\phi_{2}} \\
n_{2}^{1}=\left(1+n_{0}(1-\rho) / \rho\right)\left(1-e^{-\phi_{1}}\right) \phi_{2} e^{-\phi_{2}} \\
\quad+n_{1} \widehat{\phi}_{2} e^{-\widehat{\phi}_{2}}(1-\rho) / \rho \\
n_{2}^{2}=n_{2}-n_{2}^{0}-n_{2}^{1}
\end{array}\right] .
$$

Since the values of the endogenous variables $\left(V, \Lambda_{0}, \Lambda_{1}, \Lambda_{2}, \phi_{1}, \phi_{2}, \widehat{\phi}_{2}\right)$ are determined by equations (3.9)-(3.12), (3.17)-(3.19) and the parameters $\left(\beta, \rho, y_{1}, y_{2}, k_{1}, k_{2}\right)$, equation (3.26) completely determines the wage structure in the stationary equilibrium. At this point, it is useful to compare this structure with that of the static model (given in equation (2.3)). Clearly, $w_{0}^{0}, w_{1}^{1}$, and $w_{2}^{2}$ are the same in the two models. The reasoning why $w_{0}^{0}=0$, $w_{1}^{1}=y_{1}$ and $w_{2}^{2}=y_{2}$ is straightforward in both models, but $w_{1}^{0}, w_{2}^{0}$ and $w_{2}^{1}$ may need some explanation.

The wage $w_{1}^{0}$ is paid to a worker who had no other offers when matched with one low productivity vacancy. It is equal to the present value of the immediate outside option $\Lambda_{0}$ at the time of the wage negotiation minus the discounted future outside option while the worker is employed. The future outside option reflects the following gamble. With the exogenous probability $\rho$ the worker will become unemployed and receive the market value of being in the labor force. With the probability $(1-\rho)$ the worker will not lose his job, in which case the worker faces another gamble determined by the endogenous probability $\left(1-\left(1+\widehat{\phi}_{2}\right) e^{-\widehat{\phi}_{2}}\right)$ of finding a better job, receiving $\Lambda_{2}$, and the probability of not getting a better wage offer and remaining with the same wage under $\Lambda_{0}$.

Wages $w_{2}^{0}$ and $w_{2}^{1}$ are similar, but with the wage reflecting matches with a lone high productivity vacancy, and a high productivity vacancy where the second best offer was from a low productivity vacancy respectively. In both cases, the wage reflects the immediate outside option and the discounted future outside option while employed - which is a gamble determined by 
the exogenous probability $\rho$ alone, since no vacancies raid workers currently employed in high productivity jobs.

\subsubsection{Efficiency}

As mentioned above, although we do not prove it here, the equilibrium of this model is constrained efficient. The efficiency of the equilibrium with on-the-job search demonstrates that commitment to a match between a low productivity job and a worker is not a desired property for social welfare and that the wage profiles of our decentralized model solve this problem of noncommitment efficiently, given the coordination problem. This result resolves a problem of inefficiency posed by Pissarides $(1994,2000)$ and Kennes (1994) concerning the optimal wage profiles of models with matching technologies and on-the-job search. The answer to the problem is simply that workers in bad jobs are paid lower wages in equilibrium to compensate for the later wage improvement associated with the movement of these employed workers into good jobs through the process of on-the-job search.

\section{Quantitative Analysis}

In this section, we try to assess the quantitative significance of the model through numerical simulations. We think of this as a model of the natural rate of unemployment - where there is no cyclical component in the unemployment rate. Ideally, then, we would like to choose values of the parameters to match values of key endogenous variables with empirical data for an economy operating at its natural rate. One of the key endogenous variables in this model is residual wage dispersion, that is, wage dispersion among homogeneous workers. Data on this dispersion is hard to come by but, fortunately, Katz and Autor (1999) do provide statistics for the US economy - most recently in 1995. We therefore use data for the US, from a variety of sources, to pin down values of some of the parameters, in an idealized natural rate setting.

\subsection{Baseline Parameter Values}

The model has six parameters: $\left(\beta, \rho, y_{1}, y_{2}, k_{1}, k_{2}\right)$. The Katz and Autor (1999) study analyses weekly data. With an annual discount rate of $5 \%$, this implies a weekly discount factor of $\beta=0.999$. We chose a weekly value of $\rho=0.0089$, which corresponds to a monthly value of $3.5 \%$, used by Hall (2004). (This is also the annual average of the total nonfarm separation rate recorded in 2001, the first annual data point available in the Job Openings and Labor Turnover Survey at the BLS. $)^{11}$ To focus on an equilibrium with

\footnotetext{
${ }^{11}$ As mentioned above, Cao and Shi (2000) consider numerical simulations of their directed search model with wage posting. While they do not calibrate their model to match
} 


\begin{tabular}{|l|l|l|}
\hline Statistic & Model & US Data \\
\hline Mean Wage & 254.88 & 255 \\
\hline Unemployment Rate & 4.08 & 4.0 \\
\hline Vacancy Rate & 1.47 & 1.5 \\
\hline Standard Deviation Log Wage & 0.3100 & 0.603 \\
\hline $90 \%$ - 10\% Log Wage (Residual) & 1.0344 & 1.15 \\
\hline
\end{tabular}

Table 1: Comparing Statistics

on-the-job search, given the values of $\beta$ and $\rho$, we restricted our choices of $\left(y_{1}, y_{2}, k_{1}, k_{2}\right)$ and to satisfy the condition stated in Proposition 2, part (a). We set $y_{1}=150$, which is at the lower end of the observed distribution, and chose the values of $y_{2}, k_{1}$ and $k_{2}$ to match the average weekly wage for males in 1982 dollars (\$255), the "natural" rate of unemployment $(4 \%)$ and the vacancy rate of $1.5 \% .{ }^{12}$ These values were $y_{2}=1037, k_{1}=1450$ and $k_{2}=75399$.

The values of $k_{1}$ and $k_{2}$ may seem quite high, when considering weekly costs. However, in the model, these costs terminate once a vacancy is filled - and vacancies are filled quite quickly in equilibrium. In reality, there are fixed costs when creating jobs, and these can be quite large when considering that capital is used to match with a worker. Following Pissarides (2000), to keep the state vector as small as possible, we model these costs as flow costs. As a consequence, to balance the expected present value of the infinite stream of benefits from a job, the costs (which are expected to persist for a small number of periods) appear large. Note, however, that they are small relative to the equilibrium values of the matches $\Lambda_{1}$ and $\Lambda_{2}$ presented in equation (4.2) below.

\subsection{Results}

Table 1 compares some of the statistics from this example with those from US data.

The values of the parameters were chosen so that the mean wage, the unemployment rate, and the vacancy rate were close to those in the data. Katz and Autor report that the standard deviation of the overall log wage in the US overall in 1995 was 0.603 . In the model, the corresponding figure is 0.3083 . - approximately $51 \%$ of the figure in the data. This is $75 \%$ of the $2 / 3$ figure they attribute to residual wage dispersion.

\footnotetext{
any moments in the data, they do choose the monthly separation rate to be $3 \%$.

${ }^{12}$ The actual unemployment rate in 1995 was $5.6 \%$. We chose $4 \%$ as our target because because the unemployment rate settled down to that number in 2000 - arguably, this was the natural rate. The $1.5 \%$ figure for the vacancy rate used registered vacancies from the OECD Main Economic Indicators.
} 
The result is closer for another statistic reported by Katz and Autor. They report the differences of the 90th and 10th percentiles of the log wage distribution, for the residual wage distribution: 1.15. In the model, this figure is 1.0344 - approximately $90 \%$ of Katz and Autor's number.

\subsubsection{The Equilibrium Wage Distribution}

The following matrix, corresponding to equation (3.26), presents the equilibrium weekly wage distribution, $\widetilde{\Omega}_{d}$, in 1982 dollars, for this set of parameters.

$$
\widetilde{\Omega}_{d}=\left[\begin{array}{ll}
w_{0}^{0}=0 & n_{0}^{0}=0.0322 \\
w_{1}^{0}=129.47 & n_{1}^{0}=0.0974 \\
w_{1}^{1}=150 & n_{1}^{1}=0.0013 \\
w_{2}^{0}=233.45 & n_{2}^{0}=0.2576 \\
w_{2}^{1}=251.63 & n_{2}^{1}=0.5862 \\
w_{2}^{2}=1037 & n_{2}^{2}=0.0253
\end{array}\right]
$$

From (4.1), it is quite clear that both productivity dispersion and contract dispersion play important roles in wage determination in the model. For example, among workers that receive only one job offer, those that receive this offer from a high productivity vacancy receive a wage of $w_{2}^{0}=$ 233.45 , while those that receive the offer from a low productivity vacancy receive only $w_{1}^{0}=129.47$. This difference is due entirely to productivity dispersion. However, among those workers that take jobs with high productivity vacancies, those that had no other offer receive $w_{2}^{0}=233.45$, those whose second-best offer came from a low-productivity vacancy receive $w_{2}^{1}=251.63$, while those whose second-best offer came from another high productivity vacancy receive $w_{2}^{2}=1037$. The difference of these three wages is driven purely by contract dispersion.

Equation (4.1) also shows that, in the stationary equilibrium, most workers are in good jobs. Adding $n_{1}^{0}$ and $n_{1}^{1}$, we can see that only $9.87 \%$ of workers are in bad jobs. Altogether, $86.91 \%$ of workers are in good jobs. However, very few $(2.52 \%)$ are paid the top wage of $w_{2}^{2}=1037$. Due to contract dispersion, $25.76 \%$ earn only $w_{2}^{0}=233.45$, while $58.62 \%$ earn $w_{2}^{1}=251.63$. This leaves $4 \%$ unemployed. As in empirical studies, this distribution is hump-shaped, and significantly skewed to the right, with a small fraction of people earning high wages. Figure 1 provides a plot of this distribution. 


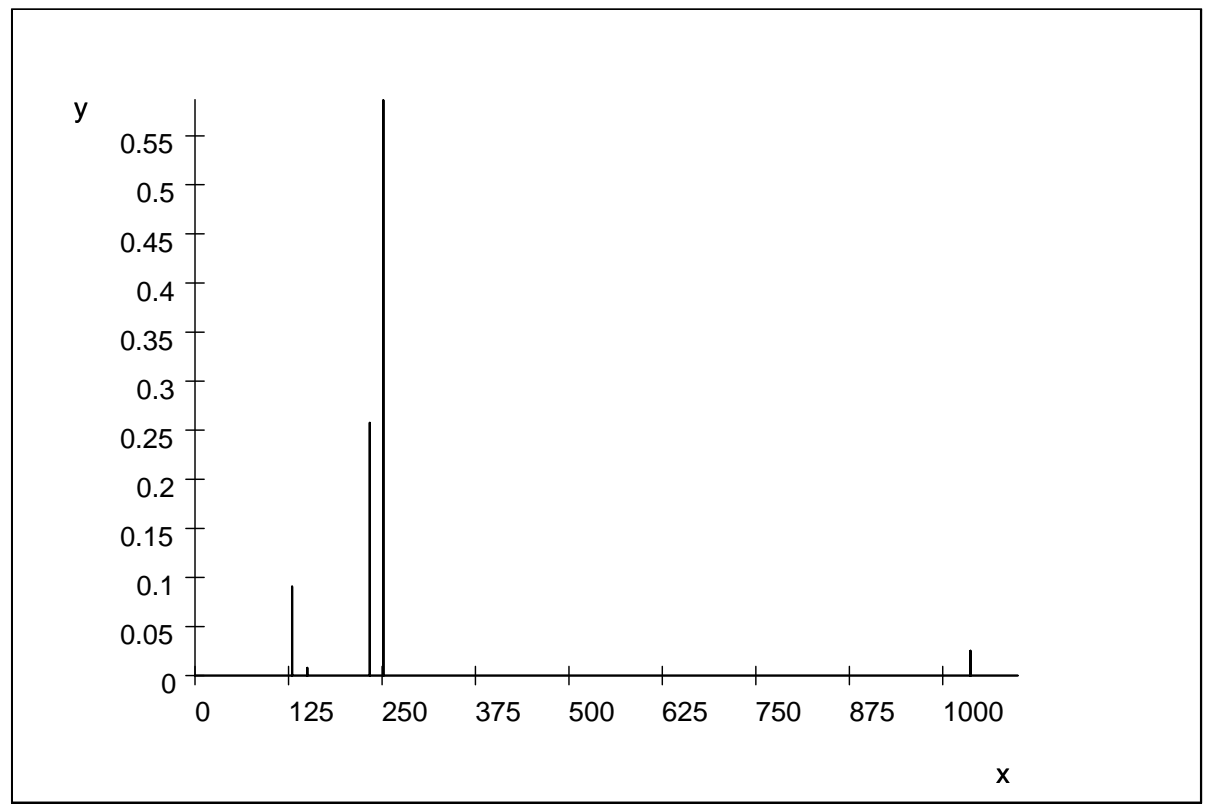

Figure 1: The Equilibrium Wage Distribution

\subsubsection{Quantity and Value of Jobs}

The following matrix shows the calibrated stationary equilibrium values of the tightness variables for the different jobs, and the present values of the surplus associated with each type of match.

$$
[\widetilde{\phi}, \widetilde{\Lambda}]=\left[\begin{array}{ll}
\widehat{\phi}_{2}=0.0517 & \Lambda_{0}=235,548 \\
\phi_{2}=0.0711 & \Lambda_{1}=237,385 \\
\phi_{1}=0.1658 & \Lambda_{2}=316,787
\end{array}\right]
$$

Although the vacancy/unemployment ratio for bad jobs is more than twice that for good jobs, as mentioned above, the vast majority of workers are in good jobs in the stationary equilibrium. On-the-job-search is significant enough to drive this result. Workers in bad jobs know that they will not stay there for very long. The following table represents the one-week transition matrix for wages in the stationary equilibrium. ${ }^{13}$

$\begin{array}{lllllll} & w_{0}^{0} & w_{1}^{0} & w_{1}^{1} & w_{2}^{0} & w_{2}^{1} & w_{2}^{2} \\ w_{0}^{0} & .7891 & .1308 & .0115 & .0561 & .0101 & .0024 \\ w_{1}^{0} & .0070 & .9424 & .0001 & .0005 & .0487 & .0013 \\ w_{1}^{1} & .0070 & .0012 & .9413 & .0005 & .0487 & .0013 \\ w_{2}^{0} & .0070 & .0012 & .0001 & .9916 & .0001 & .0000 \\ w_{2}^{1} & .0070 & .0012 & .0001 & .0005 & .9912 & .0000 \\ w_{2}^{2} & .0070 & .0012 & .0001 & .0005 & .0001 & .9911\end{array}$

\footnotetext{
${ }^{13}$ We would like to thank an anonymous referee for suggesting the inclusion of this table. The values 0.0000 are not to be taken literally as 0 . They are both approximately 0.0000214 .
} 
Workers in bad jobs, earning, for example, $w_{1}^{0}=129.47$, know that the probability of getting a higher paid job in the near future is quite high: with a $5.06 \%$, chance $(.0001+.0005+.0487+.0013)$, they will get one next week. The liklihood of getting one within a month is $18.75 \%$. Within a year, this will happen with a $93.28 \%$ probability. There are two routes to higher paid jobs for someone earning $w_{1}^{0}$. First, they may be separated from their current bad job, and earn more through successful off-the-job search (over the period of a week, this occurs with probability $0.07 \%$ ). Second, they may be successful with on-the-job search. Over a week, this occurs with the significantly higher probability of $4.99 \%$. Thus, on-the-job search plays a major role in determining the shape of the wage distribution, by moving most workers into good jobs eventually, with a peak density at $w_{2}^{1}$. This particular feature is shared with the model in Burdett and Mortensen (1998). However, the fact that there exists a higher wage, beyond the peak density, comes from the existence of contract dispersion in the model wages differ among workers in good jobs because some workers have more good jobs approach them than others. This feature is not present in Burdett and Mortensen (1998), but is shared with Postel-Vinay and Robin (2002) who, as here, allow for counteroffers and ex post wage adjustment. Also key to keeping the density smaller at the highest wage is the fact that job arrival rates are smaller for on-the-job searchers than for unemployed workers. In Postel-Vinay and Robin (2002), this difference in the arrival rates is assumed. Here, it is a result that emerges in equilibrium. ${ }^{14}$

\subsubsection{Endogenous Arrival Rates and Equilibrium Turnover}

From equation (4.2), it can be seen that the probability of a worker receiving a good job offer, when unemployed $\left(1-e^{-\phi_{2}}=0.069\right)$ is higher than the receiving one when already employed in a bad job $\left(1-e^{-\widehat{\phi}_{2}}=0.0504\right)$. This occurs because of the more significant outside option that a worker in a bad job has: if successfully recruited, due to the auction mechanism, he must be paid $w_{2}^{1}=251.63$, rather the wage $w_{2}^{0}=233.45$ paid to a worker that was previously unemployed.

Overall, the arrival rate of job offers for workers currently employed (0.0504) is approximately one quarter the arrival rate for unemployed workers $\left(1-e^{-\phi_{1}} e^{-\phi_{2}}=0.2109\right)$. The ratio of these rates broadly consistent with empirical estimates made by Kiefer and Neumann (1993), and the parametric rates used in Postel-Vinay and Robin (2002), although the rates

\footnotetext{
${ }^{14}$ This process has the implication that the ratio $\Lambda_{2} / \Lambda_{1}=1.33$ is significantly smaller than the value of $y_{2} / y_{1}=6.91$. The values of the matches include all expected returns to both the firm and the worker. Thus, the value of $\Lambda_{1}$ takes into account the fact that the worker will, most likely, move on to a good job in the future.
} 
themselves are considerably higher. A related statistic, the aggregate equilibrium monthly job finding rate (defined as the number of matches divided by the number of unemployed) in this model is 0.599. As one might expect, this is above empirical estimates. Shimer (2004), for example estimates the average job finding rate in the US from 1951 to 2003 to be 0.343 .

The model predicts that the average spell of unemployment will last approximately 4.7 weeks. The actual length in 1995 (from the BLS) was approximately 16.6 in 1995 . However, as noted above, the unemployment rate in 1995 was $5.6 \%$, not the natural rate of $4 \%$ that we use here. In the year 2000, when the unemployment rate was $4 \%$, the average spell of unemployment lasted 12.6 weeks.

Of course, the aggregate data from the BLS does not control for heterogeneity and there are good reasons to expect that heterogeneity in the labor market increases the length of unemployment spells. ${ }^{15}$ It seems reasonable to say, though, that this model underpredicts unemployment durations, and overpredicts job finding rates. In general, the equilibrium matching process in this model appears to be more effective than is evidenced in the US economy.

\subsection{Sensitivity Analysis}

We experimented by considering ranges of values for all of the parameters, around the baseline. The results are summarized in the following tables.

\subsubsection{Changes in the discount factor $\beta$}

$\begin{array}{llllllll}\beta & .9986 & .9988 & .9990 & .9992 & .9994 & .9996 & .9998 \\ \phi_{1} & .1948 & .1801 & .1658 & .1515 & .1374 & .1232 & .1089 \\ \phi_{2} & .0642 & .0678 & .0711 & .0744 & .0775 & .0804 & .0833 \\ \widehat{\phi}_{2} & .0447 & .0483 & .0517 & .0550 & .0581 & .0610 & .0639 \\ \bar{W} & 227.60 & 241.13 & 254.88 & 268.84 & 283.02 & 297.43 & 312.06 \\ U & 3.79 & 3.93 & 4.08 & 4.25 & 4.44 & 4.65 & 4.89 \\ V & 1.51 & 1.49 & 1.47 & 1.45 & 1.42 & 1.39 & 1.36 \\ \sigma_{\log w} & .2972 & .3045 & .3100 & .3140 & .3164 & .3173^{*} & .3165 \\ 90-10 & .8972 & .9681 & 1.0344 & 1.0859 & 1.1339 & 1.1794 & 1.2224\end{array}$

This table shows how the values of key endogenous variables change as the discount factor $\beta$ ranges from 0.9986 to 0.9998 . The first thing to notice

\footnotetext{
${ }^{15}$ Specifically, when workers are heterogeneous, in the the mixed strategy equilibrium, firms place higher visit probabilities on more productive workers. With the appropriate wage determination mechanism (such as the auction we use here) this leads to a constrained efficient outcome, but raises the unemployment rate. See, for example, Julien, Kennes, and King (2005).
} 
in this table is that the entry of good jobs, both for unemployed workers $\left(\phi_{2}\right)$ and employed $\left(\widehat{\phi}_{2}\right)$, increases with $\beta$. However, the entry of bad jobs $\left(\phi_{1}\right)$ decreases. Thus, changes in $\beta$ affects the mix of jobs in equilibrium. Increases in $\beta$ increase the expected present value of the stream of future payoffs, relative to the vacancy costs that must be paid up front. This affects good jobs disproportionately, because their up front costs are higher than for bad jobs. With more good jobs created in equilibrium, this makes it less profitable to create bad jobs. The mean wage $(\bar{W})$, which is influenced mainly by the number of good jobs, is therefore increasing in $\beta$ and is quite responsive to changes in its value: a $0.12 \%$ increase in the discount factor induces a $37.1 \%$ increase in the mean wage. The unemployment rate $(U)$, which is mainly sensitive to the number of bad jobs in equilibrium, is increasing in $\beta$ as the number of bad jobs falls, and rises by more than a percentage point over the range. The vacancy rate $(V)$, which is also mainly sensitive to the number of bad jobs, is decreasing in $\beta$ as the number of bad jobs falls. Thus, changes in the discount factor cause unemployment and vacancies to move in opposite directions.

The two different measures of wage dispersion, $\sigma_{\log w}$ and $\log 90-\log 10$, are affected differently by changes in $\beta$. The $\log 90-\log 10$ statistic is strictly increasing in $\beta$ for the range considered, as more good jobs are created, and less bad ones, but $\sigma_{\log w}$ is non-monotonic in $\beta$ - initally rising, then falling. In the table, the $\sigma_{\log w}$ statistic reaches a maximum at 0.3173 , indicated by the asterisk, where $\beta=0.9996$. However, locally, at the point of the baseline, both measures of inequality rise with $\beta$.

\subsubsection{Changes in the separation rate $\rho$}

$\begin{array}{llllllll}\rho & .0076 & .0081 & .0085 & .0093 & .0097 & .0101 & .0105 \\ \phi_{1} & .0701 & .1084 & .1371 & .1951 & .2262 & .2608 & .3039 \\ \phi_{2} & .0902 & .0834 & .0775 & .0641 & .0561 & .0466 & .0340 \\ \widehat{\phi}_{2} & .0708 & .0640 & .0581 & .0447 & .0367 & .0272 & .0146 \\ W & 352.28 & 313.63 & 283.94 & 226.86 & 199.91 & 174.28 & 150.22 \\ U & 4.89 & 4.47 & 4.25 & 3.95 & 3.83 & 3.71 & 3.57 \\ V & 1.07 & 1.24 & 1.36 & 1.58 & 1.67 & 1.74^{*} & 1.73 \\ \sigma_{\log w} & .2950 & .3110 & .3122^{*} & .2986 & .2777 & .2427 & .1806 \\ 90-10 & 1.3100 & 1.2180 & 1.1224 & .8944 & .7333 & .5463 & .3296\end{array}$

This table shows how the values of key endogenous variables change as the separation rate $\rho$ ranges from .0076 to .0105 . Intuitively, the effect on entry of the separation rate is the opposite of that of the discount factor. Increases in $\rho$ reduce the expected present value of income streams. Thus, for the reasons outlined above, $\phi_{2}$ and $\widehat{\phi}_{2}$ are decreasing, and $\phi_{1}$ is increasing, in $\rho$. For analogous reasons, the mean wage is decreasing, and is quite 
sensitive to, changes in $\rho$ : a $38 \%$ increase in $\rho$ induces a $57 \%$ decrease in $\bar{W}$. The unemployment rate is affected by changes in $\rho$ through two channels - one direct and one indirect - working in opposite directions. Directly the separation rate increases the unemployment rate, for obvious reasons. However, indirectly, the unemployment rate is sensitive to the number of bad jobs in equilibrium, which is driven up by an increase in $\rho$. That is, indirectly, through bad job creation, an increase in $\rho$ reduces unemployment. In equilibrium, for this parameterization, the indirect channel is stronger than the direct one. Interestingly, the vacancy rate is nonmonotonic in $\rho$. Higher values of $\rho$ drive down the number of good jobs created, and increase the number of bad jobs. When considering aggregate vacancies, for low values of $\rho$, the second effect outweighs the first. This switches with higher values of $\rho$. Thus, for lower values of $\rho$, unemployment and vacancies move in opposite directions as $\rho$ changes; whereas, for higher values, they move in the same direction. Locally at the baseline point, they move in opposite directions. ${ }^{16}$

Once again, the measures of dispersion behave in different ways. The $\sigma_{\log w}$ statistic is hump-shaped as $\rho$ increases, reaching a maximum to the left of the baseline point. The $\log 90-\log 10$ statistic is strictly decreasing in $\rho$. As above, at the baseline, both move in the same direction.

\subsubsection{Changes in the productivity of bad jobs $y_{1}$}

$\begin{array}{llllllll}y_{1} & 120 & 130 & 140 & 150 & 160 & 170 & 180 \\ \phi_{1} & .0224 & .0839 & .1286 & .1658 & .1983 & .2278 & .2550 \\ \phi_{2} & .0772 & .0752 & .0732 & .0711 & .0690 & .0668 & .0645 \\ \widehat{\phi}_{2} & .0577 & .0558 & .0538 & .0517 & .0496 & .0474 & .0450 \\ \bar{W} & 258.63 & 255.03 & 254.55^{*} & 254.88 & 255.59 & 256.53 & 257.64 \\ U & 8.65 & 5.75 & 4.68 & 4.08 & 3.69 & 3.40 & 3.18 \\ V & 1.02 & 1.29 & 1.41 & 1.47 & 1.52 & 1.56 & 1.59 \\ \sigma_{\log w} & .3149 & .3311^{*} & .3230 & .3100 & .2957 & .2809 & .2661 \\ 90-10 & 1.2793 & 1.2009 & 1.1169 & 1.0344 & .9458 & .8632 & .7855\end{array}$

This table shows how the values of the variables change as $y_{1}$ ranges from 120 to 180 . Exactly as one should expect, larger values of $y_{1}$ induce more entry of bad jobs, and reduce the entry of good jobs. Due to the fact that most workers are in good jobs in equilibrium, changes in the productivity of bad jobs do not affect the mean wage by much (in the table a $17 \%$ change in $y_{1}$ induces only a $1.6 \%$ change in $\bar{W}$. Also, the mean wage follows a $\mathrm{U}$ shape as $y_{1}$ increases. This reflects the changing mix of wages (contract

\footnotetext{
${ }^{16}$ In a matching model with stochastic separation rates, Shimer (2004) finds that unemployment and vacancies move, counterfactually, in the same direction. This opens the possibility that, if his model were extended to allow for more than one type of job, this counterfactual correlation could be reversed.
} 
dispersion) for different $y_{1}$ values. At the baseline point, however, the mean wage is increasing in $y_{1}$. The unemployment rate falls as the number of low quality jobs increases. Thus, unemployment decreases as $y_{1}$ increases. Similarly, the vacancy rate follows the number of bad jobs created (the fall in good vacancies, as $y_{1}$ increases, is more than offset by the rise in bad vacancies) and the vacancy rate rises with $y_{1}$. Changes in $y_{1}$, therefore, unemployment and vacancies move in opposite directions. ${ }^{17}$

Once again, the $\sigma_{\log w}$ statistic is hump shaped, while the $\log 90-\log 10$ statistic is strictly decreasing in $y_{1}$. At the baseline, both are decreasing. This is intuitive - as $y_{1}$ approaches $y_{2}$, we expect dispersion to decrease.

\subsubsection{Changes in the productivity of good jobs $y_{2}$}

$\begin{array}{llllllll}y_{2} & 975 & 1000 & 1025 & 1050 & 1075 & 1100 & 1125 \\ \phi_{1} & .2286 & .2022 & .1774 & .1533 & .1295 & .1054 & .0807 \\ \phi_{2} & .0562 & .0628 & .0686 & .0738 & .0787 & .0832 & .0874 \\ \widehat{\phi}_{2} & .0368 & .0434 & .0491 & .0544 & .0593 & .0638 & .0680 \\ W & 200.67 & 222.14 & 244.14 & 266.63 & 289.58 & 313.04 & 337.13 \\ U & 3.50 & 3.71 & 3.96 & 4.23 & 4.56 & 4.96 & 5.48 \\ V & 1.55 & 1.52 & 1.49 & 1.45 & 1.41 & 1.35 & 1.28 \\ \sigma_{\log w} & .2670 & .2884 & .3041 & .3154 & .3226 & .3256^{*} & .3238 \\ 90-10 & .7168 & .8549 & .9790 & 1.0827 & 1.1684 & 1.2475 & 1.3205\end{array}$

This table shows how the values of the variables change as $y_{2}$ ranges from 975 to 1125 . Intuitively, larger values of $y_{2}$ are associated with more entry of good jobs, both for unemployed and employed workers. This drives down the number of bad jobs. Also, the mean wage is strictly increasing, and very sensitive to, the value of $y_{2}$ : a $15 \%$ increase in $y_{2}$ induces a $68 \%$ increase in $\bar{W}$. The unemployment rate, once again, is affected predominantly by the number of bad jobs: increases in the productivity of good jobs increase the unemployment rate. Similarly, vacancies are decreasing in $y_{2}$, as the fall in entry of bad jobs more than offsets the increase in entry of good jobs over the range considered. Thus, changes in $y_{2}$ move unemployment and vacancies in opposite directions.

The $\sigma_{\log w}$ statistic is hump-shaped once again, but with the peak above the baseline point - so increasing at the baseline. The $\log 90-\log 10$ statistic is strictly increasing as $y_{2}$ increases. Intutively, inequality increases as the distance between $y_{1}$ and $y_{2}$ increases. ${ }^{18}$

\footnotetext{
${ }^{17}$ This accords with the results found in Shimer (2004). He also finds that changes in productivity primarily affect wages - a result not found in this table. However, we do find this result when we consider changes in $y_{2}$.

${ }^{18}$ If we associate good jobs with jobs that require the usage of skills (which, in this environment, all workers have but only use in good jobs) then we can interpret an increase in $y_{2}$ (ceteris paribus) as skill-biased technological change. Thus, the model predicts that
} 


\subsubsection{Changes in the vacancy cost of bad jobs $k_{1}$}

$\begin{array}{llllllll}k_{1} & 1300 & 1350 & 1400 & 1450 & 1500 & 1550 & 1600 \\ \phi_{1} & .2103 & .1953 & .1805 & .1657 & .1510 & .1361 & .1210 \\ \phi_{2} & .0961 & .0698 & .0705 & .0711 & .0718 & .0725 & .0732 \\ \widehat{\phi}_{2} & .0517 & .0517 & .0517 & .0517 & .0517 & .0517 & .0517 \\ \bar{W} & 254.56 & 254.64 & 254.75 & 254.88 & 255.03 & 255.22 & 255.46 \\ U & 3.55 & 3.71 & 3.89 & 4.08 & 4.30 & 4.55 & 4.84 \\ V & 1.54 & 1.52 & 1.50 & 1.47 & 1.45 & 1.42 & 1.39 \\ \sigma_{\log w} & .3087 & .3092 & .3097 & .3100 & .3103 & .3104^{*} & .3103 \\ 90-10 & 1.0106 & 1.0182 & 1.0261 & 1.0344 & 1.0407 & 1.0457 & 1.0505\end{array}$

This table shows how the values of the variables change as $k_{1}$ ranges from 1300 to 1600. As noted in the proof of Proposition 2, the entry of good jobs aimed at currently employed workers is independent of the value of $k_{1}$. This is a direct implication of the fact that vacancies created to go after employed workers only do not compete directly with low type vacancies. However, as expected, the entry of bad jobs decreases and the entry of good jobs (aimed at unemployed workers) increases with $k_{1}$. The average wage, which responds mostly to the number of good jobs, increases a small amount: a $23 \%$ increase in $k_{1}$ induces only a $0.35 \%$ increase in $\bar{W}$. The unemployment rate, which responds mostly to the number of bad jobs, increases with $k_{1}$ - by more than a full percentage point over the range. The vacancy rate falls as $k_{1}$ increases - so unemployment and vacancies move in opposite directions.

The $\sigma_{\log w}$ statistic is hump-shaped once again, with the peak above the baseline point - so increasing at the baseline. The $\log 90-\log 10$ statistic is strictly increasing as $k_{1}$ increases. Intuitively, increases in $k_{1}$ encourage the entry of good jobs, depress the entry of bad jobs, and raise inequality measures locally.

this type of technological change would would increase residual wage dispersion. We thank Alok Kumar for suggesting this interpretation. 


\subsubsection{Changes in the vacancy cost of good jobs $k_{2}$}

$\begin{array}{llllllll}k_{2} & 70000 & 72000 & 74000 & 75399 & 77000 & 79000 & 81000 \\ \phi_{1} & .0951 & .1229 & .1486 & .1658 & .1848 & .2080 & .2311 \\ \phi_{2} & .0857 & .0803 & .0750 & .0711 & .0667 & .0610 & .0551 \\ \widehat{\phi}_{2} & .0647 & .0600 & .0552 & .0517 & .0477 & .0425 & .0370 \\ \bar{W} & 306.08 & 286.64 & 267.79 & 254.88 & 240.36 & 222.62 & 205.32 \\ U & 5.15 & 4.66 & 4.29 & 4.08 & 3.88 & 3.67 & 3.48 \\ V & 1.32 & 1.39 & 1.44 & 1.47 & 1.50 & 1.53 & 1.55 \\ \sigma_{\log w} & .3151 & .3169^{*} & .3142 & .3100 & .3032 & .2914 & .2755 \\ 90-10 & 1.2213 & 1.1561 & 1.0866 & 1.0344 & .9572 & .8545 & .7436\end{array}$

This table shows how the values of the variables change as $k_{2}$ ranges from 70000 to 81000 . As expected, increases in the cost of good vacancies reduce the entry of these vacancies, both for employed and unemployed workers. The entry of bad jobs responds positively to fill the gap. The loss of good jobs drives down the average wage, and the increase of bad jobs reduces the unemployment rate and drives up the aggregate vacancy rate. Once again, unemployment and vacancy rates move in opposite directions. The $\sigma_{\log w}$ statistic is hump-shaped, and the hump is to the left of the baseline point. The $\log 90-\log 10$ statistic is strictly decreasing in $k_{2}$. Thus, at the baseline, both measures of inequality fall as the cost of good jobs increases.

\subsubsection{Equilibria without On-the-job Search}

When $k_{2}$ is driven up beyond the upper bound in part (a) of Proposition 2, into the range identified in part $(\mathrm{b}),\left(k_{2}=89676.58\right.$ for this parameterization) on-the-job search is choked off. As conjectured in Section 3.4 above, this induces a significant decrease in the number of high productivity jobs offered $\left(\phi_{2}=0.0163\right)$ and increase in the number of low productivity jobs $\left(\phi_{1}=0.3626\right)$. In this case, average wages fall to $\$ 132.87$, the unemployment rate falls to $2.8 \%$, and the vacancy rate falls to $1.05 \%$. Since most jobs are of one type in this equilibrium $\left(n_{1}=0.9307\right)$ both measures of inequality drop precipitously: the $\sigma_{\log w}$ statistic and the $\log 90-\log 10$ fall to 0.0698 and 0.1585 respectively. Going further, and driving $k_{1}$ beyond the upper bound in part (a) of Proposition 2, into the range identified in part (c), $\left(k_{1}=4242.07\right)$ so that no low productivity jobs are created, drives down inequality even more. ${ }^{19}$ We conclude from this that both technology disper-

\footnotetext{
${ }^{19}$ In Julien, Kennes, and King (2003) we calibrate a model with only one type of job, so that it matches the mean wage and the unemployment rate. Although some wage disparity exists in the equilibrium of that model, due to contract dispersion, quantitatively it is quite small. For example, the $\sigma_{\log w}$ statistic is only 0.01 .
} 
sion and on-the-job search are important for the quantitative performance of this model as a theory of wage dispersion.

\section{Conclusions}

According to this analysis, a simple lack of coordination among employers, when choosing workers to approach for jobs, could be responsible for much of the wage dispersion that we observe among narrowly defined groups of workers. In this model, if employers are able to coordinate on any of the multiplicity of pure strategy equilibria then all workers are paid their outside option, all jobs are of the same type, and no dispersion exists. In the absence of this coordination the unique symmetric mixed strategy equilibrium, arguably, represents a focal point. ${ }^{20}$ In this equilibrium we observe significant dispersion - comparable to that observed empirically. Viewed in this light, the two-thirds of "unexplained" wage dispersion can be attributed largely to plain luck on the part of workers.

The analysis also suggests that, in the absence of risk aversion, unless policymakers are willing and able to somehow coordinate employers, the allocation is as efficient as it can be. It should be noted also that this absence of coordination favors workers - and policies designed to coordinate would have redistributive consequences. This efficiency result, now commonplace in "directed search" models such as this, is quite different from results derived in "undirected search" with heterogeneous jobs. ${ }^{21}$ This is one of the key differences in these approaches.

In the presence of risk aversion, a clear potential role for policy arises. The challenge becomes to design policies that can eliminate some of the risk without reducing the allocative efficiency of the equilibrium. We look forward to future research that tackles this issue.

\footnotetext{
${ }^{20}$ Montgomery (1991), citing Tirole (1986), also argues that mixed strategy equilibria can be viewed as "reduced form" pure strategy Bayesian equilibria where players have "a little" private information.

${ }^{21}$ See, for example, Acemoglu (2001), Davis (2001), and the discussion in Ljungquist and Sargent (2000).
} 


\section{Appendix}

\subsection{Proof of Proposition 2}

First, using equations (3.9)-(3.12) to find $\Lambda_{2}-\Lambda_{1}$, and equation (3.19), we find the following condition determining $\widehat{\phi}_{2}$ :

$$
e^{\widehat{\phi}_{2}}=\beta(1-\rho) \widehat{\phi}_{2}+\beta(1-\rho)+\frac{y_{2}-y_{1}}{k_{2}}
$$

This equation is of the form $e^{x}=a x+b$, where $a$ and $b$ are constants. Let $\widehat{b}_{2}=\beta(1-\rho)+\left(y_{2}-y_{1}\right) / k_{2}$ and $\widehat{a}_{2}=\beta(1-\rho)<1$ to write equation (A.1) as:

$$
e^{\widehat{\phi}_{2}}=\widehat{a}_{2} \widehat{\phi}_{2}+\widehat{b}_{2}
$$

Using equations (3.17)-(3.19), one obtains: $\left(k_{2}-k_{1}\right) e^{-\widehat{\phi} 2}=e^{-\widehat{\phi} 2}$, or

$$
\phi_{2}-\widehat{\phi}_{2}=-\ln \left(\frac{k_{2}-k_{1}}{k_{2}}\right)>0
$$

Let $\gamma=\ln \left(\frac{k_{2}-k_{1}}{k_{2}}\right)$, so that equation (A.2) can be re-written as: $\widehat{\phi}_{2}=\phi_{2}+\gamma$. Then use this in equation (A.1) to get:

$$
\begin{gathered}
e^{\phi_{2}+\gamma}=\beta(1-\rho)\left(\phi_{2}+\gamma\right)+\beta(1-\rho)+\frac{y_{2}-y_{1}}{k_{2}} \\
e^{\phi_{2}}=e^{-\gamma}\left(\beta(1-\rho) \phi_{2}+\beta(1-\rho)(1+\gamma)+\frac{y_{2}-y_{1}}{k_{2}}\right)
\end{gathered}
$$

Now, since $e^{-\gamma}=\frac{k_{2}}{k_{2}-k_{1}}$, this equation can be written as:

$$
e^{\phi_{2}}=\beta(1-\rho) \frac{k_{2}}{k_{2}-k_{1}} \phi_{2}+\beta(1-\rho)(1+\gamma) \frac{k_{2}}{k_{2}-k_{1}}+\frac{y_{2}-y_{1}}{k_{2}-k_{1}}
$$

Now, defining $a_{2}=\beta(1-\rho) \frac{k_{2}}{k_{2}-k_{1}}$ and $b_{2}=\beta(1-\rho)(1+\gamma) \frac{k_{2}}{k_{2}-k_{1}}+\frac{y_{2}-y_{1}}{k_{2}-k_{1}}$, we can re-write this equation as:

$$
e^{\phi_{2}}=a_{2} \phi_{2}+b_{2}
$$

Now use equations (3.9)-(3.11) to obtain:

$$
\Lambda_{2}-\Lambda_{0}=\frac{y_{2}-\beta(1-\beta)(1-\rho) V}{1-\beta(1-\rho)}
$$


Using equations (3.10) and (3.11) to find $\Lambda_{2}-\Lambda_{1}$, and equation (3.12) to find $V$, substitute these into equation (3.18) to get:

$$
e^{\phi_{1}}=\frac{\beta(1-\rho)}{e^{\phi_{2}}} \phi_{1}+\frac{y_{1}+\beta(1-\rho) k_{2}\left(\phi_{2}-\widehat{\phi}_{2}\right)}{k_{1} e^{\phi_{2}}}
$$

With $\widehat{\phi}_{2}$ and $\phi_{2}$ determined in equations (A.2) and (A.4) respectively, the values $a_{1}=\frac{\beta(1-\rho)}{e^{\phi_{2}}}$ and $b_{1}=\frac{y_{1}+\beta(1-\rho) k_{2}\left(\phi_{2}-\widehat{\phi}_{2}\right)}{k_{1} e^{\phi_{2}}}$ are constants, and we may write:

$$
e^{\phi_{1}}=a_{1} \phi_{1}+b_{1}
$$

Lemma Let $x^{*}$ solve $e^{x^{*}}=a x^{*}+b$, where $a$ and $b$ are constants, then there exists

1. $\quad$ a unique $x^{*}=0$ if $f a \leq 1$ and $b \leq 1$.

2. two solutions $x^{*}=0$ and $x^{*}>0$ if $f 1<a<\infty$ and $b \leq 1$.

3. $\quad$ a unique $x^{*}>0$ if $f a<\infty$ and $b>1$.

To prove part (a) of the Proposition, we can use part (3) of the Lemma.

Clearly, $\widehat{a}_{2}<\infty$, and $a_{i}<\infty, i=1,2$. Thus, unique solutions $\widehat{\phi}_{2}>0$, $\phi_{2}>0$, and $\phi_{1}>0$ exist iff

$$
\begin{aligned}
& \widehat{b}_{2}>1 \Longleftrightarrow \frac{y_{2}-y_{1}}{1-\beta(1-\rho)}>k_{2} \text { and } \\
& b_{2}>1 \Longleftrightarrow k_{2}<\frac{y_{2}-y_{1}+k_{1}}{1-\beta(1-\rho)(1+\gamma)} \text { and } \\
& b_{1}>1 \Longleftrightarrow k_{1}<\left(y_{1}+\beta(1-\rho) k_{2}\left(\phi_{2}-\widehat{\phi}_{2}\right)\right) e^{-\phi_{2}}
\end{aligned}
$$

Since $\gamma \in(-1,0)$, it follows that $\frac{y_{2}-y_{1}}{1-\beta(1-\rho)}<\frac{y_{2}-y_{1}+k_{1}}{1-\beta(1-\rho)(1+\gamma)}$ and so $\frac{y_{2}-y_{1}}{1-\beta(1-\rho)}>k_{2}$ is the binding constraint on $k_{2}$.

For part (b) of the Proposition, we first use part (1) of the Lemma.

Clearly, $\widehat{a}_{2}=\beta(1-\rho)<1$ Hence, there exists a unique solution $\widehat{\phi}_{2}=0$ iff:

$$
\widehat{b}_{2} \leq 1 \Longleftrightarrow \frac{y_{2}-y_{1}}{1-\beta(1-\rho)} \leq k_{2}
$$

We now use part (3) of the Lemma. Clearly, $a_{i}<\infty, i=1,2$ 
Hence, there exist unique solutions $\phi_{1}>0$ and $\phi_{2}>0$ iff

$$
\begin{aligned}
& b_{1}>1 \Longleftrightarrow k_{1}<\left(y_{1}+\beta(1-\rho) k_{2}\left(\phi_{2}-\widehat{\phi}_{2}\right)\right) e^{-\phi_{2}} \text { and } \\
& b_{2}>1 \Longleftrightarrow k_{2}<\frac{y_{2}-y_{1}+k_{1}}{1-\beta(1-\rho)(1+\gamma)}
\end{aligned}
$$

Since $\gamma \in(-1,0)$, it follows that $\frac{y_{2}-y_{1}}{1-\beta(1-\rho)}<\frac{y_{2}-y_{1}+k_{1}}{1-\beta(1-\rho)(1+\gamma)}$ for all $k_{1}, k_{2}$. Therefore, $k_{2} \in\left[\frac{y_{2}-y_{1}}{1-\beta(1-\rho)}, \frac{y_{2}-y_{1}+k_{1}}{1-\beta(1-\rho)(1+\gamma)}\right] \Longleftrightarrow 0=$ $\widehat{\phi}_{2}<\phi_{2}$.

For part (c) of the Proposition, we first use part (1) of the Lemma.

Clearly, $\widehat{a}_{2}=\beta(1-\rho)<1$ and $a_{1}=\frac{\beta(1-\rho)}{e^{\phi_{2}}}<1$

Hence, there exists unique solutions $\widehat{\phi}_{2}=0$ and $\phi_{1}=0$ iff:

$$
\begin{aligned}
& \widehat{b}_{2} \leq 1 \Longleftrightarrow \frac{y_{2}-y_{1}}{1-\beta(1-\rho)} \leq k_{2} \\
& b_{1} \leq 1 \Longleftrightarrow k_{1} \geq\left(y_{1}+\beta(1-\rho) k_{2}\left(\phi_{2}-\widehat{\phi}_{2}\right)\right) e^{-\phi_{2}}
\end{aligned}
$$

We now use part (3) of the Lemma. Clearly, $a_{2}=\beta(1-\rho) \frac{k_{2}}{k_{2}-k_{1}}<\infty$. Hence there exists a unique solution $\phi_{2}>0$ iff

$$
b_{2}>1 \Longleftrightarrow k_{2}<\frac{y_{2}-y_{1}+k_{1}}{1-\beta(1-\rho)(1+\gamma)}
$$

Since $\gamma \in(-1,0)$, it follows that $\frac{y_{2}-y_{1}}{1-\beta(1-\rho)}<\frac{y_{2}-y_{1}+k_{1}}{1-\beta(1-\rho)(1+\gamma)}$ for all $k_{1}, k_{2}$. Therefore, $k_{2} \in\left[\frac{y_{2}-y_{1}}{1-\beta(1-\rho)}, \frac{y_{2}-y_{1}+k_{1}}{1-\beta(1-\rho)(1+\gamma)}\right] \Longleftrightarrow 0=$ $\widehat{\phi}_{2}<\phi_{2}$.

For part (d) of the Proposition, we first use part (1) of the Lemma. iff

Clearly, $\widehat{a}_{2}=\beta(1-\rho)<1$. Hence, there exists a unique solution $\phi_{2}=0$

$\widehat{b}_{2} \leq 1 \Longleftrightarrow \frac{y_{2}-y_{1}}{1-\beta(1-\rho)} \leq k_{2}$

We now use part (3) of the Lemma. Clearly, $a_{1}=\frac{\beta(1-\rho)}{e^{\phi_{2}}}<1<\infty$. 
Hence there exists a unique solution $\phi_{1}>0$ iff

$b_{1}>1 \Longleftrightarrow k_{1}<\left(y_{1}+\beta(1-\rho) k_{2}\left(\phi_{2}-\widehat{\phi}_{2}\right)\right) e^{-\phi_{2}}$

We now use part (1) of the Lemma again. For $\phi_{2}=0$ we need

$$
b_{2} \leq 1 \Longleftrightarrow k_{2} \geq \frac{y_{2}-y_{1}+k_{1}}{1-\beta(1-\rho)(1+\gamma)}
$$

We also need $a_{2}=\beta(1-\rho) \frac{k_{2}}{k_{2}-k_{1}} \leq 1$. This condition is re-written as $k_{2} \geq \frac{k_{1}}{1-\beta(1-\rho)}$.

Since $\frac{k_{1}}{1-\beta(1-\rho)}<\frac{y_{2}-y_{1}+k_{1}}{1-\beta(1-\rho)(1+\gamma)}$ then this condition is satisfied when $k_{2} \geq \frac{y_{2}-y_{1}+k_{1}}{1-\beta(1-\rho)(1+\gamma)}$.

\subsection{Proof of the Corollary}

This follows directly from equation (A.3) above. 


\section{References}

[1] Acemoglu, D., (2001) "Good Jobs versus Bad Jobs", Journal of Labor Economics, 19, 1-22.

[2] Acemoglu, D. and R. Shimer, (2000) "Wage and Technology Dispersion", Review of Economic Studies, 67, 587-607.

[3] Albrecht, J., P. Gautier, and S. Vroman, (2003), "Equilibrium Directed Search with Multiple Applications", Georgetown University manuscript

[4] Burdett, K. and K. Judd, (1983) "Equilibrium Price Dispersion", Econometrica, 51, 955-969.

[5] Burdett, K.. and D. Mortensen (1998) "Equilibrium Wage Differentials and Employer Size", International Economic Review, 39, 257-274.

[6] Burdett, K. S. Shi and R. Wright, (2001) "Pricing and Matching with Frictions" Journal of Political Economy, 109, 1060-1085.

[7] Cao, M., and S. Shi, (2000) "Coordination, Matching, and Wages", Canadian Journal of Economics, 33, 1009-1033.

[8] Coles, M., and J. Eeckhout, (2003) "Indeterminacy in Directed Search", Journal of Economic Theory, 111, 265-276.

[9] Davis, S., (2001) "The Quality Distribution of Jobs and the Structure of Wages in Search Equilibrium", NBER Working Paper 8434.

[10] Diamond, P., (1971) "A Model of Price Adjustment", Journal of Economic Theory, 3, 156-168

[11] Hall, R., (2004), "Employment Efficiency and Sticky Wages: Evidence from Flows in the Labor Market", Stanford University manuscript.

[12] Jansen, M., (1999) "Job Auctions, Holdups and Efficiency", European University Institute manuscript.

[13] Julien, B., J. Kennes, and I. King (2000) "Bidding for Labor", Review of Economic Dynamics, 3, 619-649.

[14] Julien, B., J. Kennes, and I. King (2001a) "Auctions and Posted Prices in Directed Search Equilibrium", Topics in Macroeconomics, Vol. 1, Issue 1, Article 1.

[15] Julien, B., J. Kennes, and I. King (2001b) "'Residual' Wage Disparity in Directed Search Equilibrium", University of Auckland Working Paper \#224. 
[16] Julien, B., J. Kennes, and I. King (2002a) "The Mortensen Rule and Efficient Coordination Unemployment", University of Auckland Working Paper \#231.

[17] Julien, B., J. Kennes, and I. King (2002b) "Auctions Beat Posted Prices in a Small Market", Journal of Institutional and Theoretical Economics, $158,548-562$.

[18] Julien, B., Kennes, and I. King (2003) "Directed Search without Price Directions", University of Auckland manuscript.

[19] Julien, B., J. Kennes, and I. King (2005) "Ex Post Bidding and Efficient Coordination Unemployment", Canadian Journal of Economics, forthcoming.

[20] Katz, L., and D. Autor (1999) "Changes in the Wage Structure and Earnings Inequality", in Handbook of Labor Economics, vol 3, O. Ashenfelter and D. Card (eds.), Elsevier Science B.V., chapter 26.

[21] Kennes, John (1994) "Underemployment, Unemployment and On-theJob Search", University of Western Ontario manuscript.

[22] Kiefer, N., and G. Neumann (1993) "Wage Dispersion with Homogeneity: The Empirical Equilibrium Search Model", in H. Bunzel et al (eds.) Panel Data and Labor Market Analysis, North Holland.

[23] King, I., (2003) "A Directed Tour of Search-Theoretic Explanations of Unemployment", New Zealand Economic Papers, 37, 245-267.

[24] Kultti, K., (1999) "Equivalence of Auctions and Posted Prices", Games and Economic Behavior, 27, 106-113.

[25] Ljungquist, L., and T. Sargent (2000) Recursive Macroeconomic Theory, MIT Press.

[26] Lu, X., and R. P. McAfee, (1996) "The Evolutionary Stability of Auctions Over Bargaining", Games and Economic Behavior, 15, 228-354.

[27] McAfee, R.P., (1993) "Mechanism Design by Competing Sellers", Econometrica, 61, 1281-1312.

[28] McAfee, R.P., and J. McMillan (1987) "Auctions and Bidding", Journal of Economic Literature, 25, 699-738.

[29] Moen E. (1997) "Competitive Search Equilibrium", Journal of Political Economy, 103, April, 385-411.

[30] Montgomery, J., (1991) "Equilibrium Wage Dispersion and Interindustry Wage Differentials", Quarterly Journal of Economics, 106, 163-179. 
[31] Mortensen, D., (1982) "Efficiency of Mating, Racing, and Related Games", American Economic Review, 72, 968-979.

[32] Peters, M., (1984) "Equilibrium with Capacity Constraints and Restricted Mobility", Econometrica, 52, 1117-1129.

[33] Pissarides, C., (1994) "Search Unemployment with On-the-Job Search", Review of Economic Studies 61, 457-475.

[34] Pissarides, C., (2000) Equilibrium Unemployment Theory 2nd Edition, Oxford University Press.

[35] Postal-Vinay, F., and J-M. Robin, (2002) "The Distribution of Earnings in an Equilibrium Search Model with State-Dependent Offers and Counteroffers", International Ecoonomic Review, 43, 989-1016.

[36] Rogerson, R., R. Shimer, and R. Wright (2004) "Search-Theoretic Models of the Labor Market: A Survey", Arizona State University manuscript.

[37] Shi, S., (2002a) "Product Market and the Size-Wage Differential", International Economic Review, 43, 21-54.

[38] Shi, S., (2002b) "A Directed Search Model of Inequality with Heterogeneous Skills and Skill-Biased Technology", Review of Economic Studies, 69, 467-491.

[39] Shimer, R., (2004), "The Cyclical Behavior of Equilibrium Unemployment and Vacancies", American Economic Review, forthcoming.

[40] Tirole, J., (1988) "Noncooperative Game Theory: A User's Manual," in The Theory of Industrial Organization, MIT Press, Cambridge.

[41] Violante, G., (2002) "Technological Acceleration, Skill Tranferability, an the Rise in Residual Inequaility", Quarterly Journal of Economics, 117, 297-338.

[42] Wang, R., (1993), "Auctions Versus Posted-Price Selling", American Economic Review, 83, 838-851. 